\title{
FURTHER OBSERVATIONS ON SKIN REACTIONS TO ANTIGENS FROM HETEROLOGOUS CESTODES IN ECHINO- COCCUS DISEASE
}

\author{
By JAMES T. CULBERTSON AND HARRY M. ROSE \\ (From the Departments of Bacteriology and Medicine, College of Physicians and Surgeons, \\ Columbia University, New York)
}

(Received for publication November 1, 1940)

Although the skin test is the most valuable single procedure for the diagnosis of echinococcus disease, its use for either the identification or the exclusion of possible infection is limited because the specific hydatid antigen is not easily obtained in many parts of the world in which suspected cases appear. In recent years, antigens derived from heterologous cestodes have been tried as substitutes for the specific hydatid substance in the immediate type of skin test and, in a number of instances, they have been found to serve the purpose about as well as those from the specific source (1). Several such skin-testing substances have been described previously by the authors (2) who have reported their diagnostic use in a small series of surgically proved cases of echinococcus disease. In the present communication, further observations on skin tests in echinococcus disease are recorded which indicate that many different species of cestodes are a potential source of antigen suitable for eliciting an immediate reaction. Some of these tests were performed directly upon patients known to have the disease, while others were carried out on normal persons by the passive transfer method of Prausnitz and Küstner (3).

\section{SKIN TESTS IN PERSONS WITH ECHINOCOCCUS DISEASE}

\section{General methods}

The preparation of antigens. The antigens used for the skin tests were comparatively crude saline extracts of the following helminths: Echinococcus granulosus (cyst membranes) from man, Taenia saginata from man, Taenia serrata from the dog, Hymenolepis fraterna from the mouse, Moniezia expansa from the sheep, Raillietina cesticillus from the chicken, Diphyllobothrium mansonoides from the cat, and Sparganum mansonoides from the monkey. The isolated cestodes were washed thoroughly with water, dried at $37^{\circ} \mathrm{C}$., and triturated in a mortar. Extracts were prepared by suspending 2 per cent of the dried powders in 0.5 per cent phenolated physiological salt solution for 2 hours at $37^{\circ} \mathrm{C}$. The suspensions were then centrifugated and the supernatant fluids decanted from the insoluble residues. Finally, the fluids were proved bacteriologically sterile and preserved in sealed ampules until used.

In addition to these whole-worm extracts, a proteinfree polysaccharide derived from Taenia crassicollis by Campbell (4) of the University of Chicago was used as a skin-testing antigen. For injection, the dry powder was dissolved in 0.5 per cent phenolated physiological salt solution. The most concentrated solution used contained $10 \mathrm{mgm}$. of polysaccharide in the $0.1 \mathrm{cc}$. skin test dose.

The method of skin testing. The skin tests were performed on the volar surface of the forearm, $0.1 \mathrm{cc}$. of each antigenic solution being injected intracutaneously. A positive reaction was considered to consist of a definite wheal, with pseudopodia. This wheal generally appeared within 5 minutes and attained its greatest limits within 10 to 15 minutes. Erythema was commonly noted about the site of injection but was not considered particularly significant. Frequently, when concentrated antigens were injected, delayed reactions characterized by local induration also were noted. These appeared within 30 minutes and sometimes lasted for from 24 to 36 hours.

The recording of skin reactions. Immediately after the injection of each antigen, the bleb formed was outlined with ink. The wheal which developed in positive tests was also outlined with ink as soon as its greatest size was attained. Tracings of these outlines were made and are shown in the figures which will be referred to presently.

\section{Experimental procedure and results}

All of the antigens used in this study were tested on a patient who had recently undergone incision and drainage of a large suppurating hydatid cyst of the liver. Many tests with the same antigens were performed at the same time upon a second proved case of echinococcus disease and some were repeated at intervals upon several other known cases of this infection. All of the antigens were also tested on the skins of normal persons.

All of the undiluted extracts elicited vigorous and immediate skin responses in the patients. When these extracts were titrated, however, some tolerated considerably greater dilution than others 
before failing to cause a skin reaction. For example, the extract of Taenia serrata elicited a reaction even after dilution 2500 times, and that of Taenia saginata after 1000 times, whereas the extracts of Sparganum mansonoides and Diphyllobothrium mansonoides failed to elicit a reaction when diluted more than 50 and 200 times, respectively. The extracts of Hymenolepis fraterna, Moniezia expansa, and Raillietina cesticillus could be diluted 500 times and still elicit a skin response. The cyst membranes of Echinococcus granulosus evidently contained the smallest available amount of antigen suitable for producing a skin response, since its extract failed to evoke a reaction when diluted more than 10 times. The purified polysaccharide of Taenia crassicollis also elicited a reaction in these patients, even when the stock solution, which contained $10 \mathrm{mgm}$. per 0.1 cc., was diluted 1000 times. Tracings of the immediate reactions obtained after the injection of the various dilutions of all the substances into one of the patients are shown in Figure 1.

None of the antigens caused an immediate reaction in any of the six normal persons tested. In two individuals, the area surrounding the site of injection of the concentrated Taenia saginata and Hymenolepis fraterna extracts promptly became slightly edematous, but the margins of the bleb never extended significantly, and no pseudopodia were formed. When these antigens were diluted as little as $\mathbf{5}$ times, no reaction whatsoever was elicited in any individual. Occasionally, in some of the normal persons, an erythematous zone about an inch in diameter developed at the site of injection 3 or 4 days after the inoculation of the antigens, but this disappeared within the next 24 hours or so, and seemed to have little or no relationship with the immediate positive reaction observed in the patients.

\section{SKIN TESTS IN PERSONS SENSITIZED LOCALLY WITH \\ SERUM FROM A PATIENT WITH ECHINOCOCCUS DISEASE (PRAUSNITZ-KÜSTNER TESTS)}

\section{General methods}

Serums from two patients with echinococcus disease and from a normal person were diluted with two parts of physiological salt solution and passed through a sterile Seitz E-K filter. One-tenth cubic centimeter of each filtrate was then inoculated intracutaneously into a series of well-separated sites in the upper arm of two normal individuals. Forty-eight hours later, these prepared sites, as well as the control sites, were injected with the stock antigenic extracts of Taenia serrata, Taenia saginata, $\mathrm{Hy}$ menolepis fraterna, Moniezia expansa, Raillietina cesticillus, and Diphyllobothrium mansonoides, and with a sample of hydatid cyst fluid. The reactions were read and recorded in the same manner as the direct tests upon the infected patients. The results of these tests with the serum from one patient and appropriate controls, as performed on two normal persons, are presented in Figure 2.

\section{RESULTS}

In all of the sites prepared by injection with the filtrates of the serums from the patients, a definite reaction to all the cestode antigens occurred, with wheals showing pseudopodia and attaining their greatest size in about 10 minutes. Delayed reactions, although in some cases definite, were mild when compared with those following the direct tests in the patients with the hydatid infection. No reaction whatsoever was observed at any of the sites prepared with the filtrate of normal serum, or at any of the antigen control sites.

\section{DISCUSSION}

The foregoing experimental work indicates that antigens capable of eliciting a skin reaction in hydatid patients can be derived from many different species of cestodes. Suitable antigens seem to occur in greatest amount in cestodes closely related to the homologous parasite, and proportionately less in distantly related forms. It is noteworthy that the homologous hydatid membrane is particularly poor in the skin-testing substance.

The presence of similar antigens in related cestodes agrees in principle with what is known for other classes of helminths. For example, antigens from apparently any mammalian schistosomum serve in skin tests for human schistosomiasis (5). Suitable antigens for this purpose are said also to occur in the comparatively remotely related liver flukes (6). Likewise, among nematodes, a considerable community of antigens is apparent. The dog heartworm Dirofilaria immitis, for example, yields antigens useful for skin testing in infections with several different human filarias (7), and a rabbit oxyurid, Passalurus ambiguus, has provided antigens for identifying infection with the human pin-worm, Enterobius vermicularis (8). The most inclusive group-reaction 


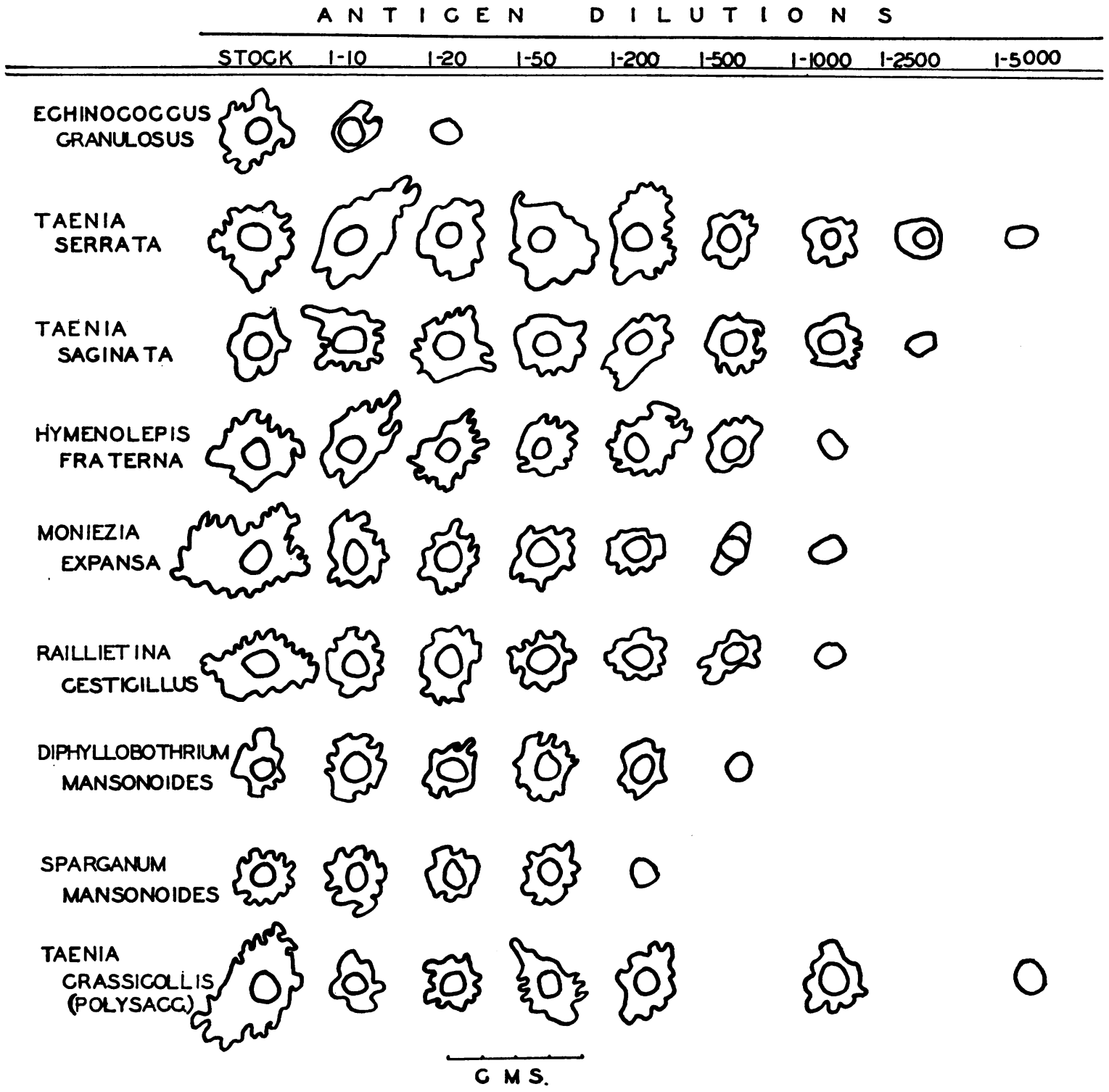

Fig. 1. Skin Reactions in a Patient with Echinococcus Disease After Injecting Progressive Dilutions of Extracts of the Following Cestodes: Echinococcus granulosus (Hydatid Membranes) from Man, Taenia serrata From tHe Dog, Taenia saginata From MAN, Hymenolepis fraterna FROM THE Mouse, Moniezia expansa from the Sheep, Raillietina cesticillus From the ChICKEN, Diphyllobothrium mansonoides from the CAT, AND Sparganum mansonoides From THE Macacus rhesus

Tests with a protein-free polysaccharide derived from cysticerci of Taenia crassicollis from the rat are also shown.

The inner circle represents the outline of the initial bleb, and the outer irregular line the greatest limits attained by the wheal in positive reactions. 
TAENIA

SERRATA

SUBJECT
ONE

SUBJECT

TWO

\begin{tabular}{|c|c|c|c|c|}
\hline 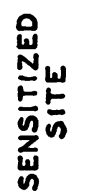 & 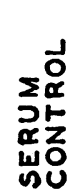 & 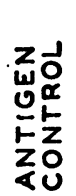 & 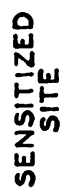 & 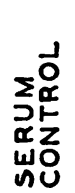 \\
\hline
\end{tabular}

TAENIA

SAGINATA

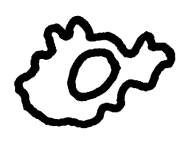

0

0

$\underbrace{5}$

00

FRATEREPAS

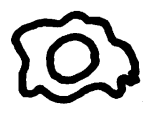

00<smiles>[GeH3]</smiles>

0

0

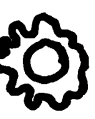

00

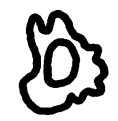

00

MONIEZIA

EXPANSA

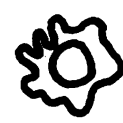

00

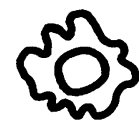

00

RAILLIE TINA CESTICILLUS

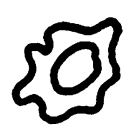

00203

00

DIPHYLLOBOTHRIUM MANSONOIDES

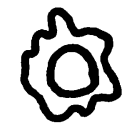

00

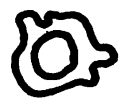

00

ECHINOCOCCUS

GRANULOSUS

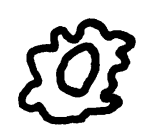

0
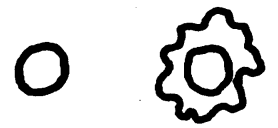

00

\section{S.}

Fig. 2. Prausnitz-Küstner Tests in Two Normal Subjects with Antigens DerIVEd FRom Taenia serrata, Taenia saginata, Hymenolepis fraterna, Moniezia expansa, Raillietina cesticillus, Diphyllobothrium mansonoides, and Echinococcus granulosus

Tests were carried out with each antigen in sites sensitized with serum from a patient with hydatid disease, or with normal serum, and in previously unprepared sites. The small circle represents the limits of the initial bleb after the antigen injection. The irregular outer line represents the greatest limits of the wheal in positive tests. 
among the nematodiases has been reported by Brunner (9), who concluded that an extract of Ascaris lumbricoides will elicit a skin test in persons with any nematode infection.

Because of the group character of the reaction in the echinococcus skin test, positive responses obtained with antigens from any of the cestodes mentioned should be viewed critically before acceptance as evidence for infection with echinococcus disease. The possibility of infection with some other type of somatic cestode (e.g., cysticercosis, sparganosis) should especially be borne in mind because powerful and confusing skin responses can be expected from them. ${ }^{1}$ Most such infections, however, can be differentiated from echinococcus disease with little difficulty through clinical procedures. Furthermore, the intestinal cestode infections also must be ruled out because they sometimes produce skin reactions. The exclusion of these intestinal infections can generally be accomplished rather simply through careful stool examinations. It is therefore the opinion and experience of the authors that, in persons suspected of hydatid infection on clinical grounds after other cestode infections have been excluded, a positive skin test with any of the antigens described provides critical evidence for the presence of this disease, especially when the test is performed with a well-diluted antigen.

Considering the observations presented here from a purely practical standpoint, passive transfer reactions to antigens prepared from cestodes such as Taenia serrata may offer an additional method of diagnosis in echinococcus disease which has an advantage in certain extraordinary circumstances. For instance, specimens of serum obtained for the Ghedini-Weinberg complementfixation reaction (11) from patients residing at a distance may also be used to perform Prausnitz-

\footnotetext{
1 Two human cases of experimentally induced sparganosis (Diphyllobothrium mansonoides) have been skin tested by Mueller (10) of the New York State College of Forestry with antigenic extracts supplied by the authors. Positive tests were obtained with extracts ${ }^{\circ}$ of Diphyllobothrium mansonoides and Taenia serrata, prepared as described in this paper, as well as with the cyst fluid of Echinococcus granulosus. The reactions were of the immediate type with definite pseudopodia and erythema, while local induration persisted for some hours thereafter.
}

Küstner tests, thus skin-testing the patient, so to speak, by proxy.

\section{CONCLUSION}

Antigens suitable for eliciting skin reactions in patients with echinococcus disease can be derived from many different cestodes, including (in addition to the specific larval parasite Echinococcus granulosus) Taenia serrata, $T$. saginata, $T$. crassicollis, Hymenolepis fraterna, Moniezia expansa, Raillietina cesticillus, and both the adult and sparganum of Diphyllobothrium mansonoides.

These antigens will also elicit skin reactions in normal persons locally sensitized passively with the serum from patients with echinococcus disease.

The authors wish to thank Dr. J. F. Mueller of the New York State College of Forestry (Syracuse) for the Diphyllobothrium mansonoides, Dr. N. R. Stoll of the Rockefeller Institute (Princeton) for the Moniezia expansa, and Drs. E. W. Price and G. W. Luttermoser of the Bureau of Animal Industry (Washington) for the Raillietina cesticillus.

\section{BIBLIOGRAPHY}

1a. Morenas, L., Utilisation du liquide de cysticerque (Cysticercus tenuicollis) comme antigène dans la réaction de Casoni. C. r. Soc. Biol., 1932, 110, 321.

b. Outeirino, J., Des recherches sur la pretendue specificite des reactions de "Ghedini-Weinberg" et de "Casoni" dans la diagnostic de l'echinococcose humaine. Ann. de med., 1935, 38, 493.

c. Chung, H.-L., and T'ung, T., The non-specificity of the so-called specific biological tests for hydatid disease. Tr. Roy. Soc. Trop. Med. and Hyg., 1939, 32, 697.

2a. Rose, H. M., and Culbertson, J. T., Diagnosis of echinococcal (hydatid) disease in man by intradermal reaction to rabbit cysticercus antigen. Proc. Soc. Exp. Biol. and Med., 1939, 41, 426.

b. Culbertson, J. T., and Rose, H. M., Allergic skin reactions in human echinococcus infection with antigens from related Taenias. Jour. Parasitol. (Suppl.), 1939, 25, 30.

c. Rose, H. M., and Culbertson, J. T., The diagnosis of echinococcus (hydatid) disease by immunologic reactions with substitute Taenia antigens. J. A. M. A., 1940, 115, 594.

3. Prausnitz, C., and Küstner, H., Studien über die ueberempfindlichkeit. Zentralbl. f. Bakt., 1921, 86, 160.

4. Campbell, D. H., A polysaccharide fraction from Cysticercus crassicollis and its rôle in immunity. J. Infect. Dis., 1939, 65, 12.

5. Fairley, N. H., and Williams, F. E., A preliminary 
report on an intradermal reaction in schistosomiasis. M. J. Australia, 1927, 2, 811.

6. Hassan, A., and Betashe, M., Fasciola gigaritica, an antigen for the skin reaction in human schistosomiasis. J. Egyptian M. A., 1934, 17, 991.

7a. Taliaferro, W. H., and Hoffman, W. A., Skin reactions to Dirofilaria immitis in persons infected with Wuchereria bancrofti. J. Prev. Med., 1930, 4, 261.

b. Fairley, N. H., The skin test and complement fixation test in filariasis. Trans. Roy. Soc. Trop. Med. and Hyg., 1932, 25, 220.

c. Rodhain, J., and Dubois, A., A contribution to the study of intradermal reactions in human filariasis. Tr. Roy. Soc. Trop. Med. and Hyg., 1932, 25, 377.

8. Tsuchiya, H., and Bauerlein, T. C., Intradermal test as an aid in the diagnosis of enterobiasis. J. Lab. and Clin. Med., 1939, 24, 627.
9. Brunner, M., Immunological studies in human parasitic infection. I. Intradermal testing with parasitic extracts as an aid in the diagnosis of parasitic infestation. J. Immunol., 1928, 15, 83.

10a. Mueller, J. F., Studies on Sparganum mansonoides and Sparganum proliferum. Am. J. Trop. Med., 1939, 18, 303.

b. Mueller, J. F., and Goldstein, F., Experimental human infection with Sparganum mansonoides (Mueller, 1935). J. Parasitol. (Suppl.), 1939, 25, 31.

11a. Ghedini, G., Ricerche sul siero di sangue di individuo affetto da cisti da echinococco e sul liquido in essa contenuto. Gazz. d. osp., 1906, 27, 1616.

b. Weinberg, M., Valeur comparée de deux procédés de laboratoire (déviation du complément et précipito-diagnostic) en vue du diagnostic de L'échinococcose. Compt. rend. Soc. Biol., 1909, 66, 133. 